\title{
Caracterização dos Compostos Químicos dos Óleos Extraídos da Casca, Arilo e Semente dos Frutos de Hymenaea stigonocarpa Mart. ex Hayne (Jatobá-do-Cerrado)
}

\section{Characterization of the Chemical Compounds of the oils Extracted from the Barks, Arils and Seeds of the Fruit of Hymenaea stigonocarpa Mart. ex Hayne (Jatobá-do-Cerrado)}

\author{
Antonio Carlos Pereira de Menezes Filho*a; Karla da Silva Malaquias ${ }^{\mathrm{b}}$; Carlos Frederico de Souza Castro \\ anstituto Federal Goiano, Campus Rio Verde, Programa de Pós-Graduaçãio Stricto Sensu em Agroquímico. GO, Brasil. \\ ${ }^{\text {b} U n i v e r s i d a d e ~ F e d e r a l ~ d e ~ G o i a ́ s, ~ I n s t i t u t o ~ d e ~ Q u i ́ m i c a, ~ D e p a r t a m e n t o ~ d e ~ Q u i ́ m i c a ~ O r g a ̂ n i c a . ~ G O, ~ B r a s i l . ~}$ \\ *E-mail: astronomoamadorgoias@gmail.com
}

\begin{abstract}
Resumo
O domínio Cerrado apresenta uma flora magnífica, composta por espécies frutíferas de grande porte, como o jatobá-do-cerrado (Hymenaea stigonocarpa), que produz anualmente volumosas quantidades de frutos, que servem de alimento para a fauna e moradores locais. O trabalho tem por objetivo avaliar, por técnicas cromatográficas por CG-MS e espectrométricas na região do infravermelho, os óleos extraídos da casca, arilo e sementes desta leguminosa. Avaliando também o rendimento de óleo extraído pelo sistema de soxlhet. Foram obtidos rendimentos lipídicos de 3,94, 1,83 e 3,47\% respectivamente para casca, arilo e semente. Os compostos químicos avaliados por cromatografia gasosa (CGMS) apresentaram compostos como: 4,6-di (1,1 - dimetiletil)-2-metil fenol, um agente antioxidante natural encontrado em vegetais, que neste estudo foi encontrado nos óleos da casca e arilo com teores de 18,90 e 11,90\% respectivamente. Teores importantes de ácido isoesteárico de $45,80 \%$ no óleo do arilo, e para o óleo da semente, porcentagens expressivas de palmitato de metila 52,90; ácidos heneicosanóico de 38,40\% e de pentacosanóico igual a 46,20\%. A análise de FT-IR apresentou grupamentos funcionais característicos de ácidos graxos como observados normalmente em outros óleos vegetais. O trabalho fornece dados importantes sobre as características químicas dos óleos extraídos do fruto de H. stigonocarpa, aumentando assim o conhecimento sobre esta espécie da família Leguminosae, que está presente no domínio Cerrado, bem como compor conhecimento científico no uso racional destes óleos nas indústrias alimentícia e farmacêutica.
\end{abstract}

Palavras-chave: Espectroscopia no Infravermelho. Cromatografia Gasosa. Constituição Química

\begin{abstract}
Cerrado domain presents a magnificent flora, composed of large fruit species, such as jatobá-do-cerrado (Hymenaea stigonocarpa), which annually produces large quantities of fruits that serve as food for the fauna and local inhabitants. The objective of this work is to evaluate the oils extracted from the bark, aril and seeds of this legume by GC-MS and spectrometric techniques in the infrared region. Also, to evaluate the oil yield extracted by the soxlhet system. Lipid yields of 3.94, 1.83 and 3.47\% respectively were obtained for bark, aril and seed. The chemical compounds evaluated by gas chromatography (GC-MS) presented compounds as 4,6-di (1,1-dimethylethyl) -2-methyl phenol, a natural antioxidant agent found in vegetables, where in this study it was found in bark oils and aryl with contents of 18.90 and $11.90 \%$ respectively. Important isostearic acid contents of $45.80 \%$ in aryl oil, and for seed oil, significant percentages of methyl palmitate 52.90; heneicosanoic acids of $38.40 \%$ and pentacosanoic acids equals to $46.20 \%$. The FT-IR analysis showed functional groupings characteristic of fatty acids as normally observed in other vegetable oils. This work provides important information on the chemical characteristics of the oils extracted from the H. stigonocarpa fruit, thus increasing the knowledge about this species of the Leguminosae family that is present in the Cerrado domain, as well as to compose scientific knowledge on the rational use of these oils in the food and pharmaceutical industries.
\end{abstract}

Keywords: Infrared Spectroscopy. Gas Chromatography. Chemical Constitution.

\section{Introdução}

O jatobá-do-cerrado é uma espécie pertencente à família Leguminosae característica do domínio Cerrado brasileiro. Esta espécie pode apresentar alturas entre 4 a 10 m produzindo dossel, sendo uma espécie frutífera anual apresentando grandes volumes de frutos com comprimento entre 6 a $18 \mathrm{~cm}$ e 3 a 6 $\mathrm{cm}$ de diâmetro. $\mathrm{O}$ fruto é constituído de uma vagem (casca externa) densa, resinosa apresentando aroma característico forte, no interior se encontra o arilo de base farinácea de cor amarela escura a amarelo claro de sabor adocicado e aroma forte, e no interior do arilo se encontram as sementes entre 3 a 6 unidades (MATUDA; MARIA NETTO, 2005; CHANG et al., 1998).

A polpa farinácea dos frutos de $H$. stigonocarpa é utilizada na cozinha no preparo de doces e mingaus, a resina produzida na casca dos frutos e tronco apresenta ação tônica, digestiva, vermífuga e anti-hemorrágica, as sementes são fonte de nutrientes para pássaros e roedores (MACHADO; AQUINO; NEVES, 2014), e possuem ação vermífuga (SILVA; RABELO; ENOQUE, 2015; RODRIGUES; CARVALHO, 2001; BOTELHO et al., 2000).

O homem já desde o início das civilizações utiliza os vegetais, as folhas, os troncos, os galhos, as flores, os frutos e as sementes oleaginosas no tratamento de alguma enfermidade, os indígenas do Brasil e das Américas são exemplos de populações que utilizam alguns tipos de óleos naturais no tratamento de doenças e como meio de cocção de seus alimentos (NOVAES et al., 2003). Vários trabalhos estão sendo desenvolvidos na avaliação destes óleos para 
comprovação da eficácia no tratamento de doenças, com ação bacteriana e fúngica, e ou como aditivo alimentício e farmacêutico no preparo de formulações (MELHORANÇA FILHO; PEREIRA, 2012; FERRONATO et al., 2007).

O óleo é um dos componentes químicos que pode ser extraído por processos de esmagamento, arraste por solvente (frio/quente) ou por fluído supercrítico. O aproveitamento das cascas, arilos e sementes do jatobá-do-cerrado pode se apresentar como um bom produto natural, que pode ser utilizado nas indústrias alimentícia e farmacêutica, apresentando porcentagens significativas de ácidos graxos importantes como isoesteárico e pentacosanóico, bem como palmitato de metila, linoleato de metila e behenato de metila. Kobori e Jorge (2005), Medina et al. (1980) e Prasad e Azeemoddin (1994) discutem sobre a utilização dos óleos das sementes de maracujá e de goiaba, apresentando resultados satisfatórios na fabricação de sabonetes, de tintas, de vernizes e após refinação e ou hidrogenação, para fins comestíveis.

É de grande importância que se avalie cientificamente as possibilidades de uso da flora do Cerrado no estudo de novos compostos com características químicas, que podem apresentar agentes antioxidantes e teores de ácidos graxos importantes na alimentação, bem como na produção de cosméticos voltados para a linha natural, que agregue a preservação do ambiente natural do Cerrado e garantindo também o uso sustentável e ecológico da espécie frutífera Hymenaea stigonocarpa.

$\mathrm{O}$ objetivo deste estudo foi caracterizar quimicamente os constituintes químicos dos óleos extraídos da casca, arilo e sementes do fruto do jatobá-do-cerrado (Hymenaea stigonocarpa) por técnicas cromatográficas e espectroscópicas, visando o aproveitamento tecnológico como possível composto em produtos alimentícios e na indústria de produtos cosmetológicos.

\section{Material e Métodos}

Os frutos do jatobazeiro-do-cerrado (Hymenaea stigonocarpa) foram coletados em uma área de preservação permanente no Instituto Federal Goiano - Campus Rio Verde, GO, com localização geográfica: 1748’03.9” S 5054’30.6”'W. Um exsicata foi depositada no Herbário do Instituto Federal Goiano - Campus Rio Verde, GO, com a seguinte identificação: IFRV Nº. 409.

Os frutos foram lavados em água corrente e deixados para secagem do excesso de água sob folhas de papel toalha. Em seguida, foram fraturados com auxílio de um martelo após assepsia com solução alcoólica $70 \%(\mathrm{~m} / \mathrm{v})$, os arilos foram retirados e utilizando um ralador para alimentos foram extraídas as sementes. As cascas dos frutos foram novamente fraturadas em fragmentos com $1 \mathrm{~cm}$ de diâmetro. $\mathrm{O}$ material foi moído separadamente em moinho de facas tipo ciclone com peneira em granulometria 32 mesh interna. Os pós foram armazenados em embalagens plásticas para alimento e levadas para refrigeração a $-8^{\circ} \pm 1,0 \mathrm{C}$ até análises.
Os óleos foram extraídos conforme descrito por IAL (2008) modificado. Foi utilizado sistema tipo soxlhet, no qual cerca de $0,150 \mathrm{~g}$ do pó foi submetido a refluxo por 6 horas, utilizado como solvente extrator Hexano. Depois da destilação do solvente em evaporador rotativo, o óleo obtido foi pesado e seu percentual calculado sobre o peso da amostra seca.

Para análise por CG-MS, seguiu conforme descrito por Milinsk et al. (2008), em que cerca de $0,10 \mathrm{~g}$ de óleo foi homogeneizado com 10,0 mL de Hexano (P.A-ACS), logo em seguida foram adicionados $0,50 \mathrm{~mL}$ de uma solução metílica de hidróxido de sódio $2 \mathrm{Mol}^{-1} \mathrm{e}$ agitou-se por 1 minuto. A solução foi adicionada em um tubo de ensaio para separação de fases. A fase sobrenadante foi coletada e transferida para um béquer, no qual foi adicionado sulfato de sódio anidro (P.A - ACS). Em seguida foi homogeneizado manualmente e filtrado em papel filtro quantitativo com gramatura (80 g/ $\mathrm{m}^{2}$ ). O filtrado foi coletado com auxílio de uma seringa, um filtro millipore $45 \mu \mathrm{m}$ foi utilizado para retirada dos cristais de sulfato de sódio. O filtrado foi armazenado em um tubo ependorff de $3 \mathrm{~mL}$.

Foi utilizado um cromatógrafo gasoso GC-Clarus 580 com detector de ionização por chama, utilizando coluna capilar DB-6 (30 m X 0,25 mm X 0,19 $\mu \mathrm{m}$ ), tendo hidrogênio como gás de arraste (fluxo de $1,0 \mathrm{~mL} / \mathrm{min}$ ) e temperatura programada com taxa de 15,0 , temperatura de 310 e aguardo de 2,00. A corrida com detentor de massa foi realizada na forma scan, com tempo de aquisição de máx. 20 min e corte do solvente em $8 \mathrm{~min}$; faixa de massas: 40 a 350; voltagem do filamento: $70 \mathrm{eV}$; voltagem do detector: $1,3 \mathrm{kV}$ : analisador do tipo quadruplo.

Os diversos constituintes químicos dos óleos da casca, arilo e sementes de $H$. stigonocarpa foram identificados através da biblioteca química do GC-Clarus 580, TurboMass e complementados com a literatura (ADAMS, 1995). Uma solução com mistura de padrões de C12-C40 foi utilizada para o cálculo do Índice de Kovats.

A análise por infravermelho, com transformada de Fourier, foi realizada em espectroscopia com infravermelho com transformada de Fourier, utilizando módulo ATR. Foram realizadas 20 varreduras por amostra. Os espectrogramas foram avaliados e plotados utilizando software Origin (Origin 2018b - Graphing \& Analysis).

O experimento para determinação do rendimento de óleo foi realizado em triplicata, com média e desvio padrão $( \pm)$. Para análise estatística se utilizou o software Past3 (Free Version 2.17) aplicando o teste de Tukey para análise de variância (ANOVA) $(\mathrm{p} \leq 0,05)$.

\section{Resultados e Discussão}

Os rendimentos de óleo para casca arilo e sementes foram iguais a $3,94 \pm 010^{\mathrm{a}} ; 1,83 \pm 0,03^{\mathrm{c}}$ e $3,47 \pm 0,13^{\mathrm{b}}$ respectivamente. Entre as três amostras de óleos foi possível observar a diferença significativa a $(p \leq 0,05)$. A casca dos 
frutos apresentou maior teor de óleo comparado com a semente. Matuda e Maria Netto (2005) obtiveram rendimento de lipídeos da farinha da semente de H. stigonocarpa igual a $5,3 \%$ superior ao obtido neste estudo.

$\mathrm{O}$ resultado deste estudo apresentou teor inferior quando comparado a outra espécie de jatobá, $H$. courbaril (jatobá-damata) 8,59\% avaliado por Sotelo (1996), ou ainda da espécie Dypterix alata (baru) 40,3\% analisado por Togashi e Sgarbieri (1994).

No Quadro 1 estão apresentados os compostos químicos encontrados nos óleos da casca, arilo e semente dos frutos de H. stigonocarpa, por cromatografia gasosa acoplada à espectrometria de massas, que indicaram os prováveis constituintes e suas concentrações nos óleos extraídos dos frutos.

Quadro 1 - Composição química dos óleos da casca, arilo e semente dos frutos de H. stigonocarpa, por cromatografia gasosa acoplada à espectrometria de massas

\begin{tabular}{|c|c|c|}
\hline \multicolumn{3}{|c|}{ Casca Fruto Jatobá } \\
\hline Composto & $\begin{array}{c}\text { Fórmula } \\
\text { Molecular }\end{array}$ & $\begin{array}{c}\text { Probabilidade } \\
(\%)\end{array}$ \\
\hline $\begin{array}{l}\text { 4,6-di (1,1 - dimetiletil)-2-metil } \\
\text { fenol }\end{array}$ & $\mathrm{C}_{15} \mathrm{H}_{24} \mathrm{O}$ & $18,90^{*}$ \\
\hline \multicolumn{3}{|c|}{ Arilo Fruto Jatobá } \\
\hline $\begin{array}{l}\text { 4,6-di (1,1 - dimetiletil)-2-metil } \\
\text { fenol }\end{array}$ & $\mathrm{C}_{15} \mathrm{H}_{24} \mathrm{O}$ & $11,90^{*}$ \\
\hline Palmitato de Metila & $\mathrm{C}_{17} \mathrm{H}_{34} \mathrm{O}_{2}$ & $17,20 *$ \\
\hline Ácido Isoesteárico & $\mathrm{C}_{18} \mathrm{H}_{36} \mathrm{O}_{2}$ & $45,80 *$ \\
\hline Ácido Paulínico & $\mathrm{C}_{20} \mathrm{H}_{38} \mathrm{O}_{2}$ & $8,26^{*}$ \\
\hline \multicolumn{3}{|c|}{ Semente Fruto Jatobá } \\
\hline Palmitato de Metila & $\mathrm{C}_{17} \mathrm{H}_{34} \mathrm{O}_{2}$ & $52,90 *$ \\
\hline Linoleato de Metila & $\mathrm{C}_{19} \mathrm{H}_{34} \mathrm{O}_{2}$ & $8,47 *$ \\
\hline Oleato de Metila & $\mathrm{C}_{19} \mathrm{H}_{36} \mathrm{O}_{2}$ & $28,00^{*}$ \\
\hline Estearato de Metila & $\mathrm{C}_{19} \mathrm{H}_{38} \mathrm{O}_{2}$ & $21,30 *$ \\
\hline Ácido Heneicosanóico & $\mathrm{C}_{21} \mathrm{H}_{42} \mathrm{O}_{2}$ & $38,40 *$ \\
\hline Behenato de Metila & $\mathrm{C}_{23} \mathrm{H}_{46} \mathrm{O}_{2}$ & $31,01 *$ \\
\hline Ácido Pentacosanóico & $\mathrm{C}_{25} \mathrm{H}_{50} \mathrm{O}_{2}$ & $46,20 *$ \\
\hline \multicolumn{3}{|c|}{$\begin{array}{l}\text { * As substâncias marcadas por um asterisco foram identificadas pol } \\
\text { aproximação, já que apresentaram probabilidade menor que } 90,00 \% \\
\text { Valores são médias de três extrações. }\end{array}$} \\
\hline Fonte: Dados da pesquisa. & & \\
\hline
\end{tabular}

O óleo da casca do fruto de H. stigonocarpa apresentou maior teor do composto químico 4,6-di (1,1 - dimetiletil)2-metil fenol com 18,90\% (composto fenólico), sendo este composto um agente antioxidante, para o arilo os maiores teores foram de 4,6-di (1,1 - dimetiletil)-2-metil fenol com $11,90 \%$ e ácido isoesteárico com $45,80 \%$, e para semente foram observados teores altos de palmitato de metila com 52,90\%, ácido pentacosanóico com 46,20\% e ácido heneicosanóico com 38,40\%. Freitas (2007) encontrou para óleo de semente de uva palmitato de metila, linoleato de metila, oleato de metila e estearato de metila. Já Matuda e Maria Netto (2005) avaliaram a composição química parcial da semente de H. stigonocarpa, na qual encontraram teores de ácido palmítico $8,9 \%$, esteárico $4,7 \%$, óleico $31,6 \%$, linolêico $52,8 \%$, linolênico $1,2 \%$, eicosanóico $0,8 \%$, saturados $14,4 \%$ e insaturados $85,6 \%$.

Na Figura 1 estão apresentados os espectrogramas no infravermelho com transformada e Fourier para os óleos da casca, arilo e sementes de H. stigonocarpa (jatobá-docerrado).

Figura 1 - Espectros por infravermelho com transformada de Fourier (FT-IR) dos óleos da casca, arilo e semente de $H$. stigonocarpa

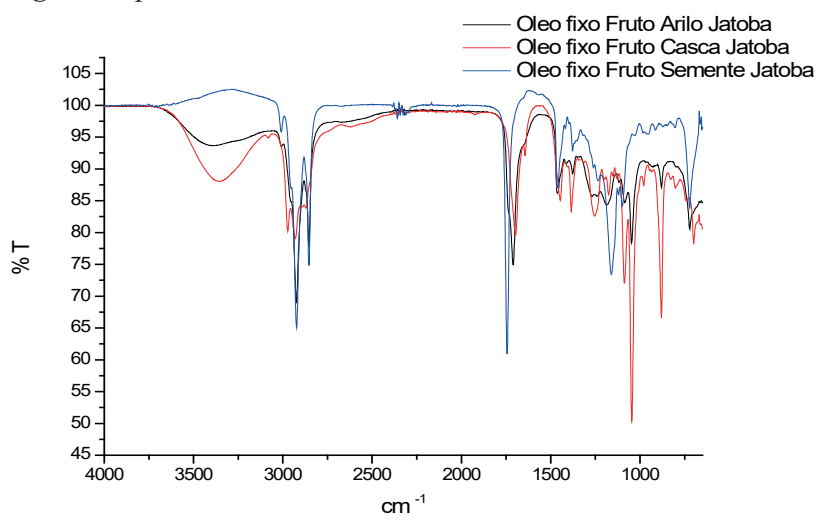

\% T = Taxa de Transmitância, $\mathrm{cm}^{-1}=$ área de varredura do espectro no infravermelho entre 4000 a $650 \mathrm{~cm}^{-1}$.

Fonte: Dados da pesquisa.

Os espectros foram sobrepostos para facilitar a visualização das absorções nas bandas entre 4000 a $650 \mathrm{~cm}^{-1}$ e apresentando os principais grupamentos vibracionais de ácidos graxos encontrados nos óleos da casca, arilo e sementes de H. stigonocarpa.

Os óleos da casca, arilo e semente dos frutos de $H$. stigonocarpa apresentam bandas características de ácidos carboxílicos, já que os óleos são compostos característicos de ácidos graxos de cadeia longa. Na Figura 1 para casca apresentou banda em $3345,82 \mathrm{~cm}^{-1}$ referente às hidroxilas das carboxilas dos ácidos graxos livres em ligações de hidrogênio (SILVERSTEIN, WEBSTER, KIEMLE, 2013).

Uma banda em 3009,12 $\mathrm{cm}^{-1}$ refere à absorção da ligação $\mathrm{H}-\mathrm{C}$ das duplas ligações presentes em ácidos graxos insaturados no óleo da semente. Bandas em 2972,39; 2953,80; 2930,12; 2923,65; 2923,04 e 2853,37 $\mathrm{cm}^{-1}$ do óleo da casca, arilo e semente, representam o grupo funcional $\mathrm{C}-\mathrm{H}$ do esqueleto hidrocarbônico. Este modo representa o estiramento vibracional simétrico e assimétrico do grupo $\mathrm{C}-\mathrm{H}$, grupos metílicos. Lima, Nascimento e Costa (2017) observaram o grupo C-H em bandas em 2843 e $2933 \mathrm{~cm}^{-1}$ em óleos de soja, canola, milho, girassol, crambe e palma.

Em 1744,03 e 1709,58 $\mathrm{cm}^{-1}$ nos óleos da semente e arilo se referem à absorção da carbonila de ésteres carboxílicos. Lima, Nascimento e Costa (2017) encontraram uma banda em 1757 $\mathrm{cm}^{-1}$ avaliando 6 óleos vegetais. No óleo da casca em 1253,81, 1404,81 , no arilo em 1463,99 e na semente em $1404,81 \mathrm{~cm}^{-1}$ corresponde à vibrações de deformação axial de C-O e de deformação angular de $\mathrm{O}-\mathrm{H}$ aparecendo em espectros de ácidos carboxílicos (SILVERSTEIN; WEBSTER; KIEMLE, 2013). Em 1160,11; 1087,25 e $1046,04 \mathrm{~cm}^{-1}$ referem à 
absorção do grupo funcional C-OH. Banda em 1697,16 refere às vibrações de deformação axial de $\mathrm{C}=\mathrm{O}$ (SILVERSTEIN; WEBSTER; KIEMLE, 2013). Reda et al. (2005) encontraram absorções para este grupo funcional em 1163 e $1099 \mathrm{~cm}^{-1} \mathrm{em}$ óleos das sementes de limão rosa e siciliano.

De acordo com Tena, Aparicio, García-González (2017), o espectro no infravermelho possui três regiões, região do espectro I corresponde ao grupo vibracional O-H entre 3700 a $3100 \mathrm{~cm}^{-1}$, na região do II grupo correspondente ao grupamento vibracional $\mathrm{C}=\mathrm{O}$ entre 1850 a $1550 \mathrm{~cm}^{-1} \mathrm{e}$ região III grupo vibracional C-H entre 1000 a $800 \mathrm{~cm}^{-1}$. Os óleos vegetais apresentam semelhanças químicas e espectros no infravermelho próximos ao deste estudo e da literatura analisada.

\section{Conclusão}

Os resultados para teores lipídicos, cromatografia gasosa acoplada a detector de massas (CG-MS) e análises por espectroscopia no infravermelho com transformada de Fourier da casca e arilo do fruto do jatobá são dados científicos inéditos, que vão compor cientificamente meios para avaliação genética, ecológica, morfoanatômica e de conservação desta espécie.

Ênfase deve ser dada ao composto 4,6-di (1,1 - dimetiletil)2-metil fenol, que foi observado na casca e arilo dos frutos de H. stigonocarpa, que possui característica antioxidante importante para o combate aos radicais livres como o oxigênio singlet. Estudos futuros com aplicação destes óleos no estudo e desenvolvimento de novos medicamentos dermatológicos de uso tópico podem apresentar excelentes resultados no uso contra o envelhecimento precoce da pele, como também em estudos contra o câncer de pele.

\section{Agradecimentos}

Ao Instituto Federal Goiano - Campus Rio Verde, a Central Analítica Multiusuário, a Universidade Federal de Goiás - Campus Jataí, CAPES, CNPq e FAPEG pela bolsa de mestrado para o primeiro autor.

\section{Referências}

ADAMS, R.P. Identification of essential oil componentes by gas cromatography/mass spectroscopy, Carol Stream: Allured, 1995.

BOTELHO, S.A. et al. Aspectos morfológicos de frutos, sementes, plântulas e mudas de jatobá-do-cerrado (Hymenaea stigonocarpa Mart. ex Hayne) - Fabaceae. Rev. Bras. Sementes, v.22, n.1, p.144-152, 2000 .

CHANG, Y.K. et al. Development of extruded snacks using Jatoba (Hymenaea stigonocarpa Mart.) flour and cassava starch blends. J. Sci. Food Agriculture, v.78, n.1, p.59-66, 1998.
FERRONATO, R. et al. Atividade antimicrobiana de óleos essenciais produzidos por Baccharis dracunculifolia DC. e Baccharis uncinella DC. (Asteraceae). Rev. Bras. Farmacol., v.17, n.2, p.224-230, 2007.

FREITAS, L.S. Desenvolvimento de procedimentos de extração do óleo de semente de uva e caracterização química dos compostos extraídos. Porto Alegre: UFRGS, 2007.

KOBORI, C.N.; JORGE, N. Caracterização dos óleos de algumas sementes e frutas como aproveitamento de resíduos agroindustriais. Rev. Ciênc. Agrotecnol., v.29, n.5, p.1008-1014, 2005.

LIMA, K.F.F.; NSCIMENTO, B.Z.; COSTA, A.P.O. Síntese de biocombustíveis a partir de diferentes óleos vegetais utilizando catalizador heterogêneo à base de nióbio. Braz. J. Production Engineering, v.3, n.1, p.1-13, 2017.

MACHADO, N.G.; AQUINO, B.G.; NEZES, G.A.P. C. Espécies nativas de plantas frutíferas em uma área de Cerrado em Mato Grosso, Brasil. REMOA, v.14, n.3, p.3306-3315, 2014.

MATUDA, T.G.; MARIA NETTO, F. Caracterização química parcial da semente de jatobá-do-cerrado (Hymenaea stigonocarpa Mart.). Ciênc. Tecnol. Alimentos, v.25, n.2, p.353-357, 2005.

MEDINA, J.C. et al. Maracujá: da cultura ao processamento comercialização. São Paulo: ITA, 1980.

MELHORANÇA FILHO, A.L.; PEREIRA, M.R.R. Atividade antimicrobiana de óleos extraídos de açaí e de pupunha sobre o desenvolvimento de Pseudomonas aeruginosa e Staphylococcus aureus. Rev Biosc. J., v.28, n.4, p.598-603, 2012.

MILINSK, M.C. et al. Comparative analysis of eight esterification Methods in the quantitative determination of vegetable oil fatty acid methyl esters (FAME). J. Braz. Chem. Soc., v.19, n.8, p.1475-1483, 2008.

PRASAD, N.B.L.; AZEEMODDIN, G. Characteristics and composition of guava (Psidium guajava L.) seed and oil. J. Am. Oil Chem. Soc., v.71, n.4, 1994.

REDA, S.Y. et al. Caracterização dos óleos das sementes de limão rosa (Citrus limonia Osbeck) e limão siciliano (Citrus limon), um resíduo agroindustrial. Rev. Ciênc. Tecnol. Aliment., v.25, n.4, p.672-676, 2005.

RODRIGUES, V.E.G.; CARVALHO, D.A. Plantas medicinais no domínio dos cerrados. Lavras: UFLA, 2001.

SILVA, A.F.; RABELO, M.F.R.; ENOQUE, M.M. Diversidade de angiospermas e espécies medicinais de uma área de Cerrado. Rev. Bras. Plantas Med., v.17, n.4, p.1016-1030, 2015.

SOTELO, A. The nutritive value of wild Mexican legumes with a potential for nutritional use. In: NWOKOLO, E.; SMARTT, J. (Ed.). Foods and feed from legumes and oilseeds. London: Chapman \& Hall, 1996. p.33-48.

TENA, N.; APARICIO, R.; GARCÍA-GONZÁLEZ, D. L. Virgin olive oil stability study by mesh cell-FTIR spectroscopy. Talanta, v.167, p.453-461, 2017. doi: https://doi.org/10.1016/j. talanta.2017.02.042

TOGASHI, M.; SGARBIERI, V. C. Caracterização química parcial do fruto do baru (Dypterix alata Vog.). Ciênc. Tecnol. Aliment., v.14, n.1, p.85-95, 1994. 